\title{
Research on Campus Education Information System Based on Internet of Things and Artificial Intelligence Decision
}

\author{
Hetiao Hong (D) \\ Hangzhou Normal University, Hangzhou Zhejiang 311121, China \\ Correspondence should be addressed to Hetiao Hong; hht@hznu.edu.cn
}

Received 27 July 2021; Revised 9 September 2021; Accepted 15 September 2021; Published 4 October 2021

Academic Editor: Rajesh Kaluri

Copyright (c) 2021 Hetiao Hong. This is an open access article distributed under the Creative Commons Attribution License, which permits unrestricted use, distribution, and reproduction in any medium, provided the original work is properly cited.

\begin{abstract}
Because of the different reasons between regions, the distribution of educational resources is also different, the development of each school is unbalanced, and the degree of campus education informationization is different. The complex functional structure not only does not facilitate teachers and students but also leads to many problems: the prevention and prevention of campus life safety. It is difficult to keep and use multiple cards owned by one person. Software and education platform cannot be seamlessly connected, and there are various barriers between data and data and people and data. The lack of learning materials leads to the inequality of information. There are no good feedback and solution between teachers and students. It is difficult to manage accurately with a large number of people. This study will be based on the Internet and artificial intelligence technology, to explore how to study a large (or super large), concise and efficient, and excellent performance of campus education information system; this system can meet the teachers and students no matter what year, month, and day of a large number of visits. For some problems in the process of building the system, actively optimize and refine them. After functional testing and analysis of the system, the experimental results show that the interface function of the new system is stable, the usability test is better than the feedback experience of the original system, the response time is reduced by $21.6 \%$ on average, and the overall power consumption of the system is reduced by about $1.43 \%$ on average.
\end{abstract}

\section{Introduction}

With the rapid development of the times and the impact of new technologies, all walks of life have changed their faces, and the education industry is no exception. Especially in the past two years, the global epidemic has seriously affected the academic process. Primary schools, junior high schools, senior high schools, and higher education institutions should build a platform integrating learning, living, monitoring, safety, and other functions for teachers and students to use and facilitate command and arrangement in case of emergencies. The Internet of Things and artificial intelligence technology are introduced into the campus, integrated with educational information, and a variety of rich application scenarios are designed and applied to meet the daily study and life of teachers and students, accelerate the completion of the modern process of educational informationization, keep up with the pace of the times, and build an intelligent campus. The literature [1] realizes the virtual scene simulation and multimedia information interaction design of multimedia information platform, intelligent classroom, library interactive platform, and student information management system on intelligent multimedia information processing terminal. The literature [2] discusses the introduction of Internet of Things technology into intelligent management and the combination of management concepts and methods with artificial intelligence technology, which has an impact on life. On the basis of analyzing the current situation of medical device management, the literature [3] incorporates the innovative achievements of information technology such as electronic signature technology, big data analysis technology, Internet of Things technology, artificial intelligence, and cloud services into the daily work of medical device management. The literature [4] introduces the domestic artificial intelligence popularization education resources and the exploratory work of artificial intelligence technology popularization on this platform. The literature [5] systematically introduces the research status of industry 
standard system related to Internet of Things and introduces the general standard classification method, hierarchical architecture, conceptual model, and system table in UPIoT application layer. The literature [6], based on campus security management, is aimed at establishing an intelligent mobile information system in colleges and universities, which adopts Windows media player along RTP/RTSP protocol. The literature [7] analyzes the application of Internet of Things in the construction of intelligent campus in colleges and universities in detail. The literature [8] compares the campus information systems of three British universities and obtains the functions that should be possessed on an ideal CWIS. The literature [9] introduces the application methods and significance of big data and cloud computing technology in intelligent campus. The literature [10] introduces an intelligent sensor network and applies the technology of intelligent sensor network to the research of campus environmental management information system model. The literature [11] introduces the architecture design of big data platform of BI application system. This building has outstanding advantages in cost, scalability, and scalability, and the realization of BI analysis function plays an important role in the strategic decision-making of colleges and universities. The literature [12] eliminates the "isolated island" in university information system and provides effective data basis for teachers and students' work, study, and daily life. The literature [13] proposes a new algorithm and user support system based on users' personal data and multiattribute preferences and proposes an effective lecture allocation method. The document [14] was based on VRML and JavaScript, the client programming, design, and implementation of online virtual campus system literature. The literature [15] takes the design of virtual campus card system under microservice architecture as the goal and designs the virtual campus card system. As an important educational link in cultivating innovative talents, under the background of the development of Internet and artificial intelligence, many colleges and universities are constantly applying new technological achievements, which must be reformed to meet the requirements of cultivating innovative talents facing the information society, establish and own their own campus information systems, change the basic environment of traditional education and teaching, and improve the overall level and application of education and teaching. The development of information society also provides environment and conditions for this reform; under the background of Internet and artificial intelligence, the construction of educational informationization has played a role in promoting the teaching, scientific research, and student training in colleges and universities, which will effectively promote the informationization and modernization of higher education, which is also the requirement and inevitable result of educational informationization. The method proposed in this paper runs well in the system, but in the whole campus system, the system expands more. In this way, the performance of the whole system will decline, and the adoption of intelligent systems requires better equipment requirements and network environment. The key research work in the future needs to improve the system response time and server throughput, especially in the context of wireless networks, using multiprotocol mechanism. When different network structures are accessed, the system is continuously accessed to improve the application effect of the whole system.

\section{Theoretical Basis of System Development}

2.1. Internet of Things Technology. Internet of Things [16, 17] is a new technology in the 21 st century, which has a good development trend in China and has gradually become a very important technology in the information age. It requires sensors to collect and process information, and at the same time, it exchanges information through the network, and the real and virtual worlds have completed a great leap. The Internet of Things involves a wide range and has many application levels.

2.2. AI Artificial Intelligence Technology. Artificial intelligence [18], also known as AI, has never stopped the research on intelligent machines, hoping to create advanced machines similar to human intelligence and ability and even put forward the theory of what should happen when intelligent robots surpass human development. In addition, people have created a series of books and audio-visual works related to artificial intelligence to tell their expectations and worries about artificial intelligence. But so far, the development of artificial intelligence is not ahead of schedule, there are many defects and drawbacks, and the core technology needs further research.

2.3. Network Upgrade Technology. So far, $4 \mathrm{G}$ network basically covers the whole campus. However, due to the limitation of $4 \mathrm{G}$ technology, with the passage of time, the network gradually becomes stuck, and sometimes, even the network is disconnected. Therefore, it is necessary to update the network. In this network upgrade, the latest $5 \mathrm{G}$ network technology will be used to upgrade the bandwidth to $5 \mathrm{G}$, and the specificity of the campus network will be strengthened to prevent unknown access and attacks from outside, and various authentication methods [19] will be adopted to facilitate integration with the new system.

2.4. ETL Technology. In the ETL technology, which is mature, we can understand it as the process of building a building. The actual application process is shown in Figure 1.

ETL technology, that is, data warehouse technology, extracts, cleans, transforms, and loads all kinds of data into data warehouse. We can also use a metaphor to understand it as the process of building a building. Figure 1 shows the practical application process, in which the functions of ETL are data extraction, cleaning and transformation, data summary, data federation, data synchronization, data migration, and data distribution.

2.5. Information Security Technology. Information security is a very important issue. Criminals often attack computer software or hardware in various ways all over the world: stealing network information, causing serious troubles to countless people, spam calls and spam sale information, human flesh search, personal pictures and audio leakage, 


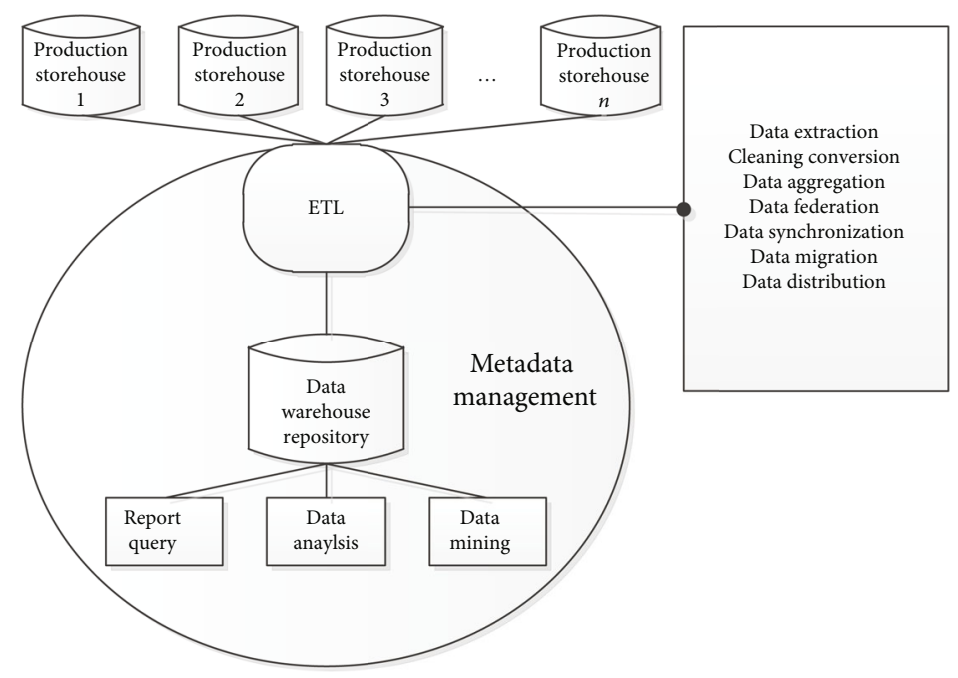

Figure 1: Practical application process of ETL.

Trojan virus, fraudulent links, and gambling propaganda. Our system needs to prevent malicious attacks, tampering, destruction, and rejection of individuals or computers that have not been accessed through formal channels, so as to ensure the confidentiality and security of information. In order to ensure information security, the system needs technical personnel to maintain and supervise the system frequently and often make up for system loopholes. For this system, we will mainly use five major information security technologies: firewall technology, information encryption technology, identity authentication technology, security protocol, and intrusion detection system. Figure 2 shows the classification diagram of information security technology.

As shown in Figure 3, the firewall operation diagram.

2.6. Apriori Association Algorithm. The Apriori algorithm uses a progressive search method to find the relation formation conditions in the database, which is composed of connection and interruption processes. We set the minimum support $(s)$ and the minimum confidence $(C)$.

(1) Find all frequent itemsets, and the frequency is greater than or equal to the minimum support $(s)$

(2) All frequent itemsets can be found by its frequent itemset

(3) The association rules should satisfy the minimum support $(s)$ and the minimum confidence $(C)$

According to the Apriori algorithm, the purpose of campus education information system is to dig out hidden information that is usually ignored by people and find that teaching level and service need to be improved and improved from a new perspective. In Figure 4, we discuss the time consumption of minimum support. The greater the minimum support, the less time consumption. In Figure 5, with other contents fixed, the larger the amount of data found, the less time it takes.

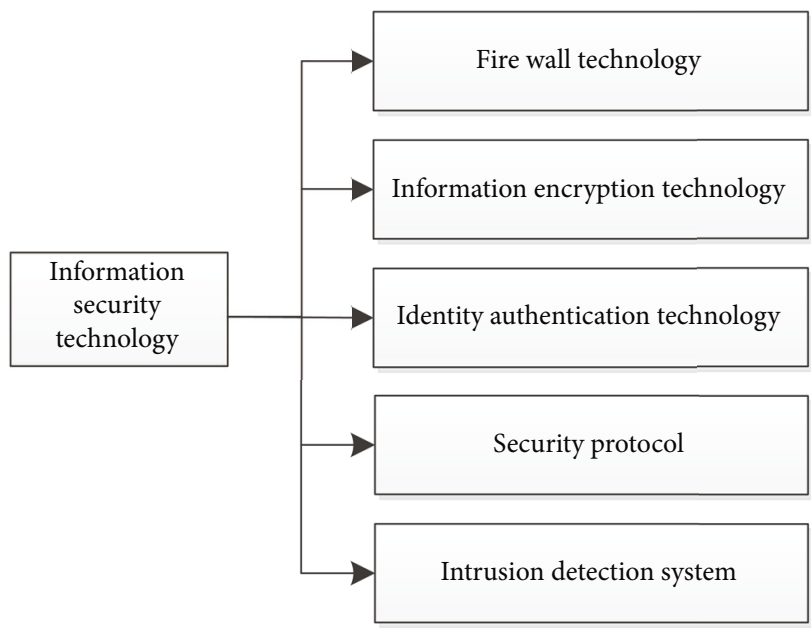

Figure 2: Classification of information security technology.

(1) Support:

$$
\begin{gathered}
(A \longrightarrow B)=P(A \cup B), \\
S(X, Y)=P(X, Y)=\frac{\text { num }(\mathrm{xy})}{\text { num(all samples })} .
\end{gathered}
$$

(2) Confidence:

$$
\begin{array}{r}
(A \longrightarrow B)=P(B \mid A), \\
C(x Y)=P(x \mid Y)=\frac{P(x y)}{P(y)} .
\end{array}
$$

2.7. Decision Tree Algorithm. The decision tree algorithm classifies information through a series of rules. 


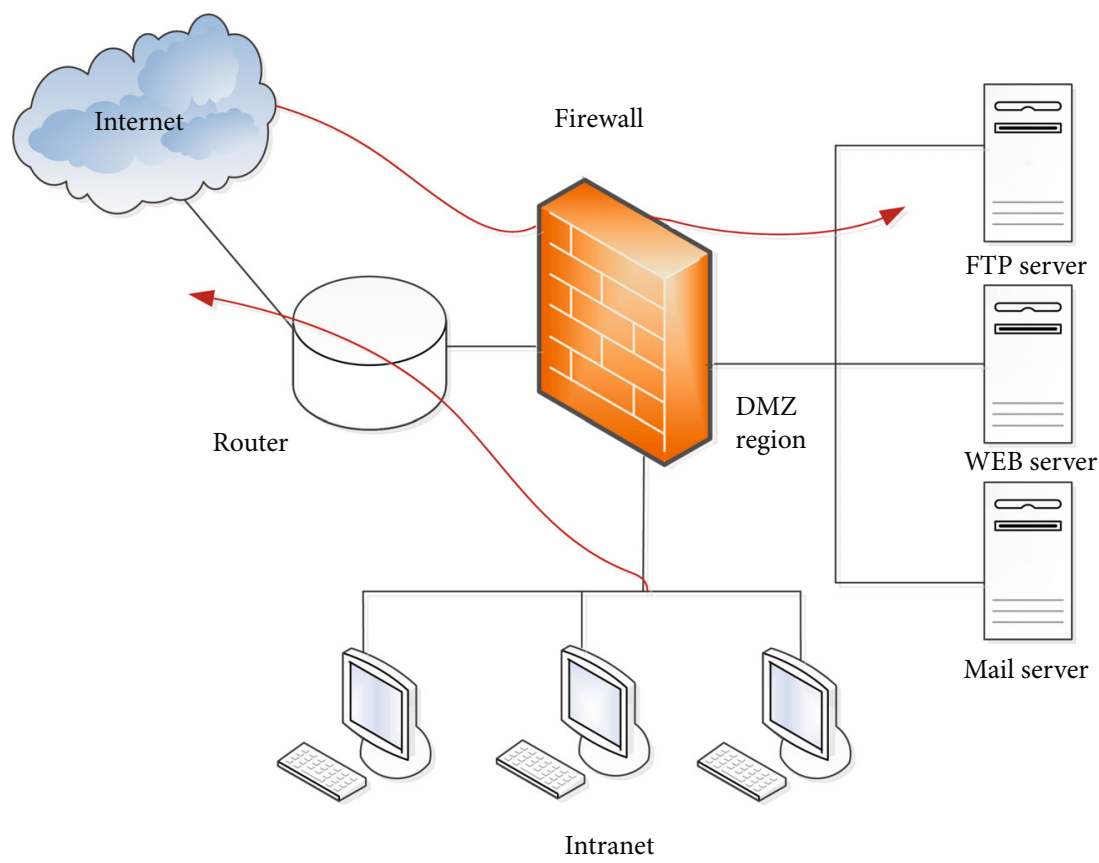

FIGURE 3: Schematic diagram of firewall operation.

Time consuming (s)

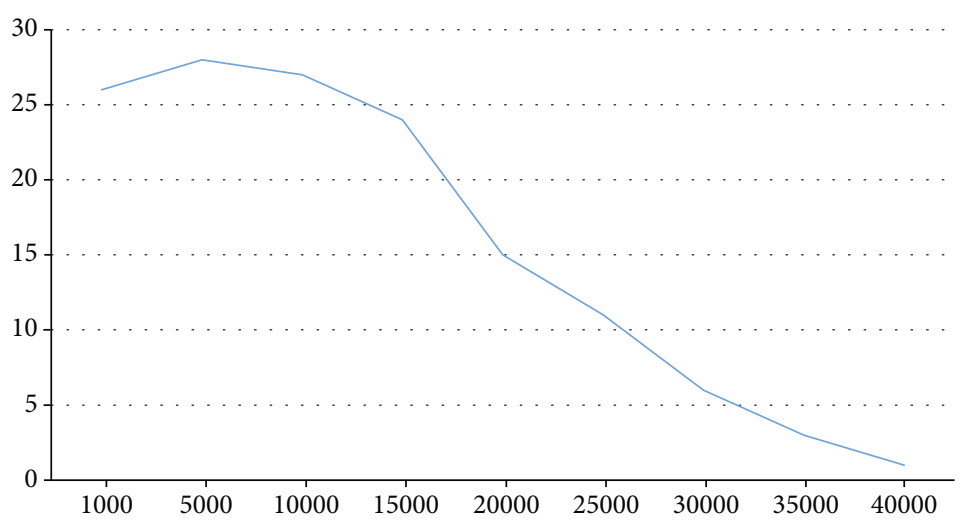

FIgURE 4: Time consumption of minimum support (s).

Time consuming (s)

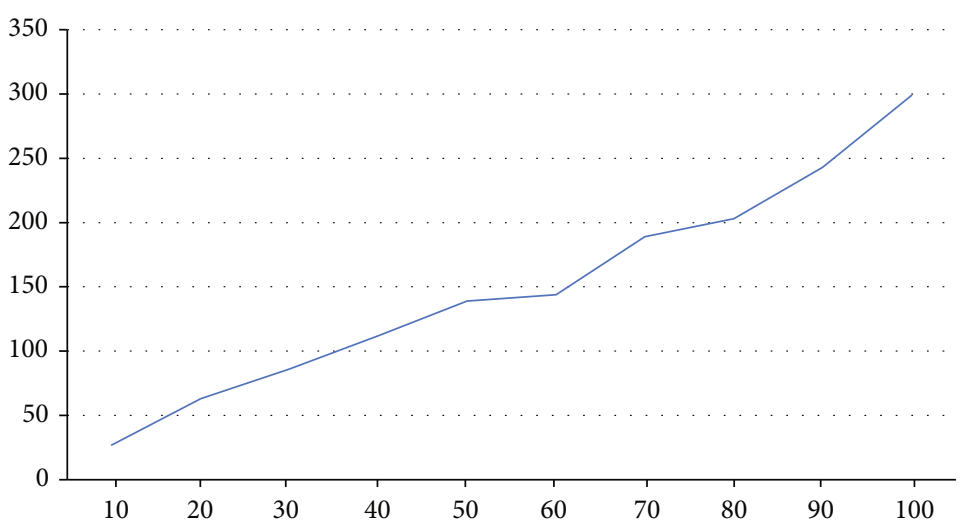

Figure 5: Time consumption of data volume $(d)$. 


\subsubsection{ID3 Algorithm}

(i) Information entropy:

$$
\begin{gathered}
P\left(x=x_{i}\right)=P_{i}, \quad i=1,2, \cdots, n, \\
H(x)=-\sum_{i=1}^{n} \log _{2} p_{i} .
\end{gathered}
$$

(ii) Conditional entropy:

$$
H(Y \mid X)=\sum_{i=1}^{n} p_{i} H\left(Y \mid X=x_{i}\right), \quad p_{i}=P\left(x=x_{i}\right)
$$

(iii) Information gain:

$$
g(D, A)=H(D)-H(D \mid A)
$$

\subsubsection{C4.5 Decision Tree}

(i) C4.5 which is an optimization decision tree defined as follows:

$$
\$ \$ S \operatorname{plitInfo}(D)=-\sum_{j=1}^{v} \frac{\left|D_{j}\right|}{|D|} * \log _{2}\left(\frac{\left|D_{j}\right|}{|D|}\right) \$ \$ .
$$

(ii) Definition of information gain rate:

$$
\$ \$ \operatorname{GainRatio}(A)=\frac{G_{a_{i} n}(A)}{\operatorname{Spl}^{a} \operatorname{tInf}_{0}(a)} \$ \$ .
$$

2.7.3. CART Decision Tree. Carnegie Mellon University decision tree is divided into classification tree and regression tree.

(i) Gini index:

$$
\$ \$ G(D)=\sum_{k=1}^{|y|} \sum_{k^{\prime} \neq k} p_{k} p_{k}^{\prime}=1-\sum_{\mathrm{k}=1}^{|y|} p_{k}^{2} \$ \$ .
$$

\subsubsection{Continuous Value Processing}

(i) For continuous attribute $a$ :

$$
T a=\left\{\frac{a^{i}+a^{b+1}}{2} \mid 1 \leq i \leq n-1\right\} .
$$

\subsubsection{CART Regression Tree}

(i) Predictive regression continuous data:

$$
D=\left\{\left(x_{1}, y_{1}\right),\left(x_{2}, y_{2}\right),\left(x_{3}, y_{3}\right), \cdots\left(x_{n}, y_{n}\right)\right\}
$$

(ii) Selecting variable $j$ and segmentation point $s$ :

$$
\min _{j, 8}\left[\min _{C_{1}} \sum_{x_{i}}\left(y_{i}-C_{1}\right)^{2}+\min _{C_{2}} \sum_{x \varepsilon}\left(y_{i}-C_{2}\right)^{2}\right]
$$

(iii) Selecting variable and segmentation point $(j, s)$ :

$$
\begin{aligned}
R_{1}(j, 8) & =\left\{x \mid x^{(j)} \leq 8\right\}, R_{2}(\dot{j}, 8)=\left\{x \mid x^{(j)}>8\right\} \widehat{c}_{m} \\
& =\frac{1}{N_{m}} \sum_{x_{i}} y_{i}, \quad x \in R_{m}, m=1,2 .
\end{aligned}
$$

(iv) Dividing the input space into $\mathrm{m}$ regions to generate a decision tree:

$$
f(x)=\sum_{m=1}^{M} \widehat{C}_{m} I\left(x \in R_{m}\right) .
$$

(v) Solving the optimal output value with square error:

$$
\sum_{x_{i} \in R_{m}}\left(y_{i}-f\left(x_{i}\right)\right)^{2}
$$

\section{System Architecture Design}

The system is designed for data management, offline application, and online service.

(1) Unified data management refers to the platform for summarizing various data on campus, which controls the flow and storage of data; most people do not have permission to view or use this part of data

(2) The offline application part of the system mainly refers to the use of infrastructure on campus, including campus security services and life convenience services, including subsystems such as payment 


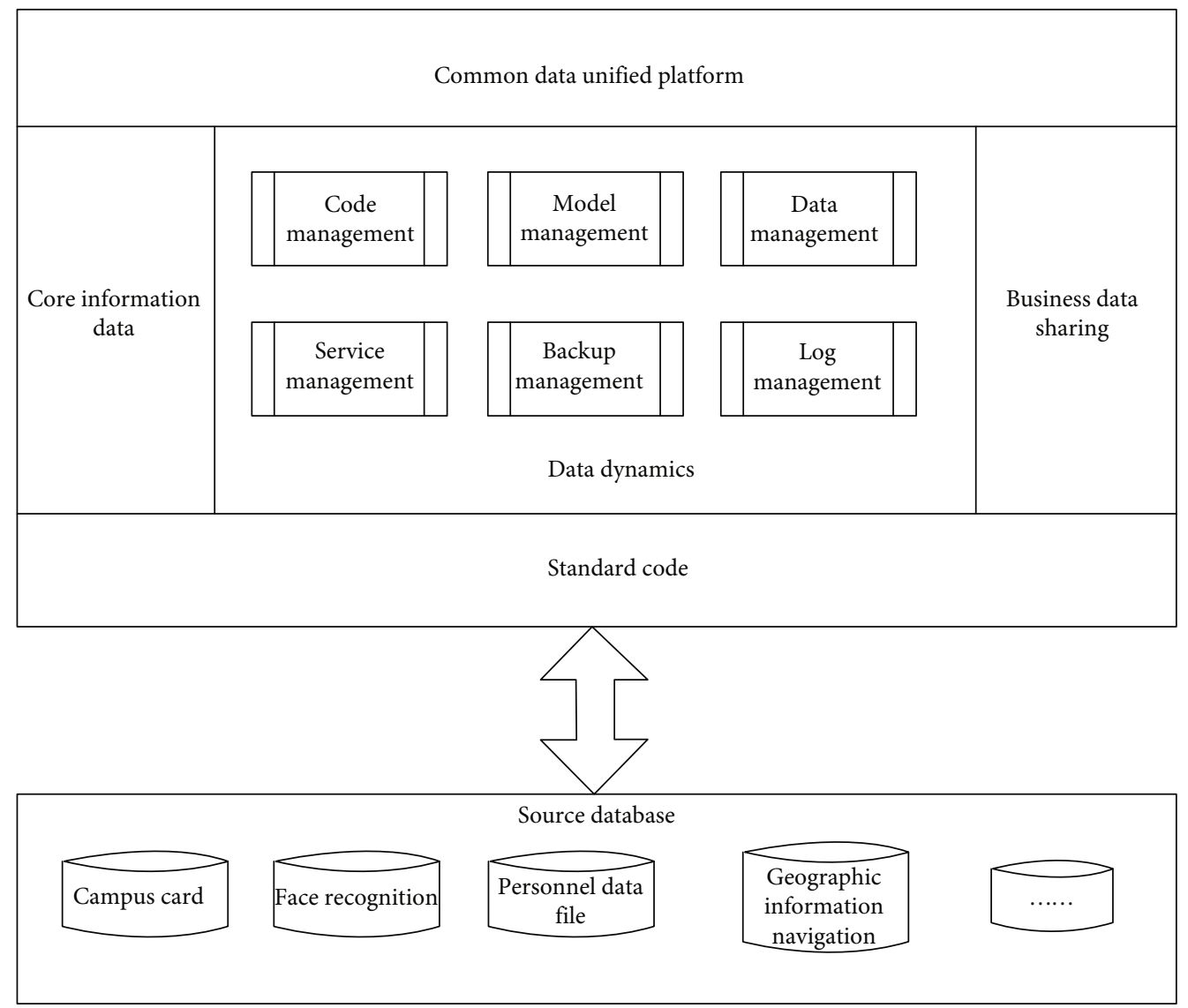

FIgURE 6: Architecture diagram of common data unified platform.

subsystem, face recognition subsystem for entering and leaving the door, classroom, and laboratory use subsystem

(3) Online services mainly refer to virtual campus services, which are mainly used through APP applications and WEB interface

Subsystem has an independent logical structure, but in the use of some subsystem functions, there will also be some other subsystem functions; this time we do not have to manually access to part of the subsystem permissions involved; the system will automatically judge and release the part of the data call and use of functions.

Offline application refers to the application of Internet of Things technology and the use of physical equipment on campus. Online service means that there is no entity at all, and all functions do not depend on physical devices on campus but are mainly used through APP applications and web interface. It can be distinguished according to whether physical equipment is needed.

\subsection{Data Management}

3.1.1. Common Data Unified Platform. The original intention of designing this unified public data platform is to process, clean, and integrate the shunted data of various subsystems and various basic original data, which need stan- dardized and unified management, so as to effectively avoid the confusion, complexity and failure of data. In the common data unified platform, the data sources are processed and cleaned by the platform and finally diverted into the relevant information data of each subsystem after standardized and unified treatment. There is a total score relationship between data source and information data. It is also convenient to record and classify data when using it. Figure 6 shows the architecture diagram of the platform.

3.1.2. Portrait of Student Behavior. A campus has many students, so it is difficult to manage. Therefore, we should use certain tools and methods to collect and sort out students' abnormal data and analyze some abnormal behaviors and violations of students. The system cannot illegally collect students' personal information. Except for some technicians, ordinary people can only apply to view the analysis results. As shown in Figure 7, it is the related data analysis process.

As shown in Figure 8, it is the platform E-R diagram.

3.1.3. Keeping of Personnel Data Files. Data files record all aspects of a person. The preservation of archives is a very confidential job, which should be highly confidential. In general, except in exceptional circumstances, no one (especially the person himself) is allowed to view and read these materials. The system will automatically update the personnel file content and, if there is an error, will have a high authority to 


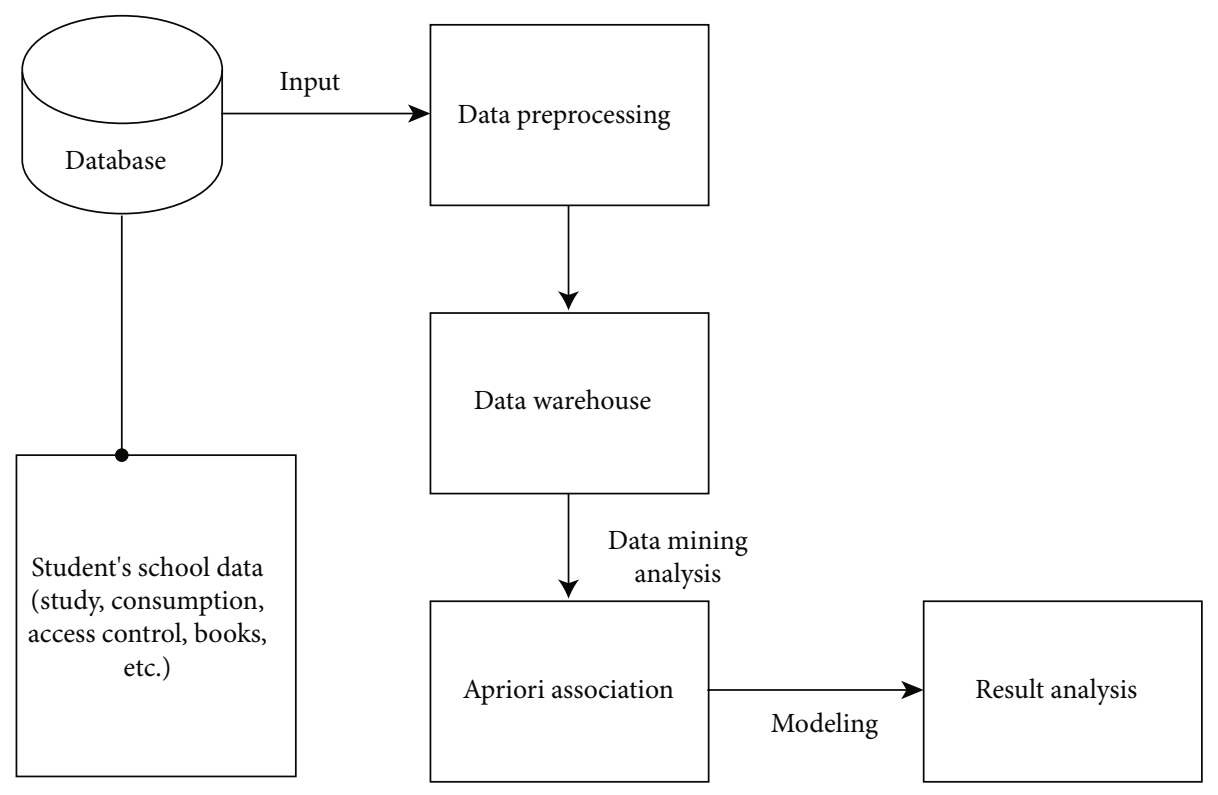

FIGURE 7: Student behavior portrait-data analysis process.

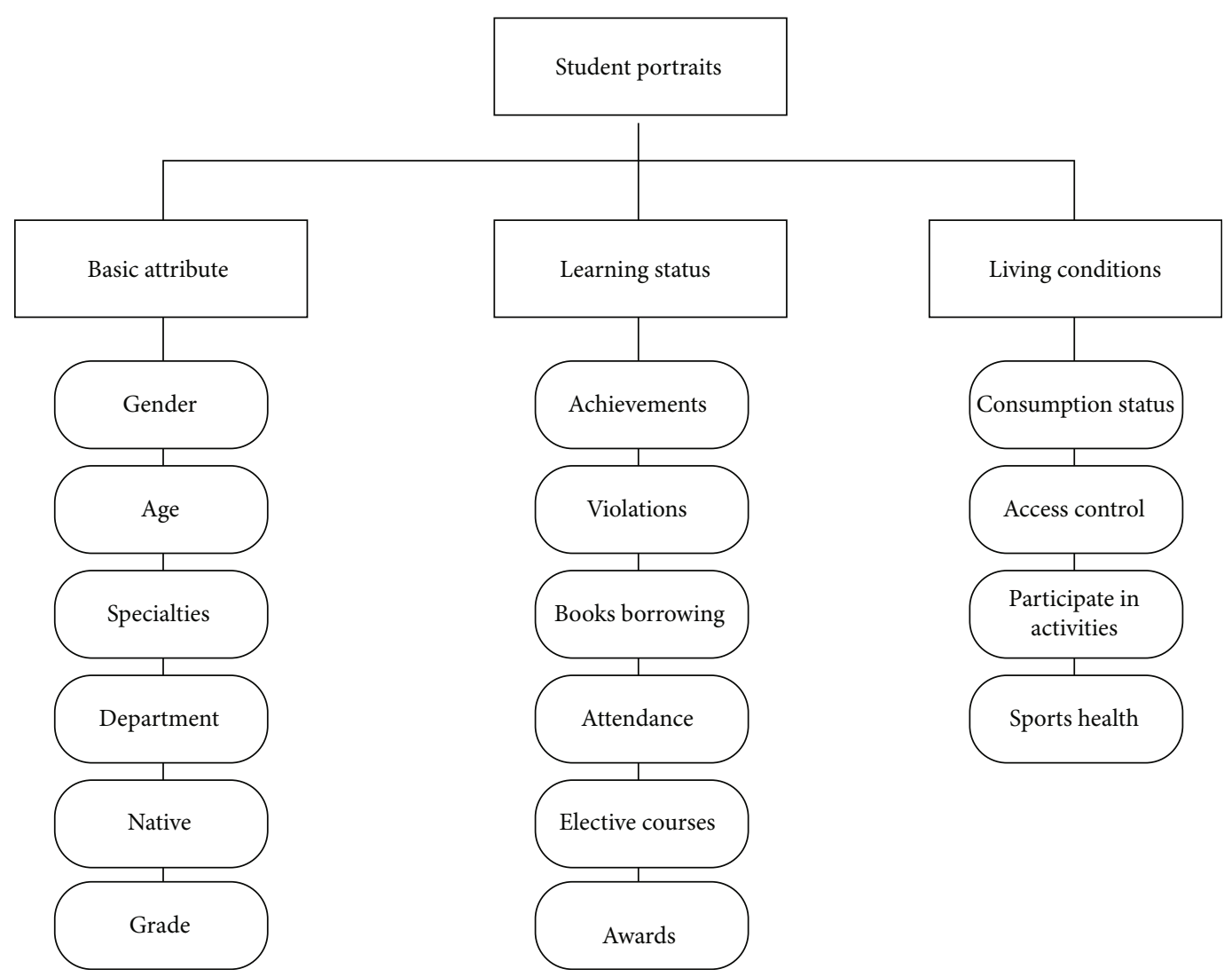

Figure 8: Platform E-R diagram.

deal with the personnel. Finally, this subsystem will make a safe backup to avoid any missing or missing files. As shown in Figure 9, it is the structure diagram of the subsystem.

3.2. Campus Security Services. Whether it is primary school, junior high school, high school, or university, campus safety is the key issue that has been emphasized again and again. In recent years, due to the development of network technology and the change of the times, data security and payment antifraud security have gradually become more and more important.

3.2.1. Data Security. It is far from enough to protect the security of data only by virtue of the security system of the 


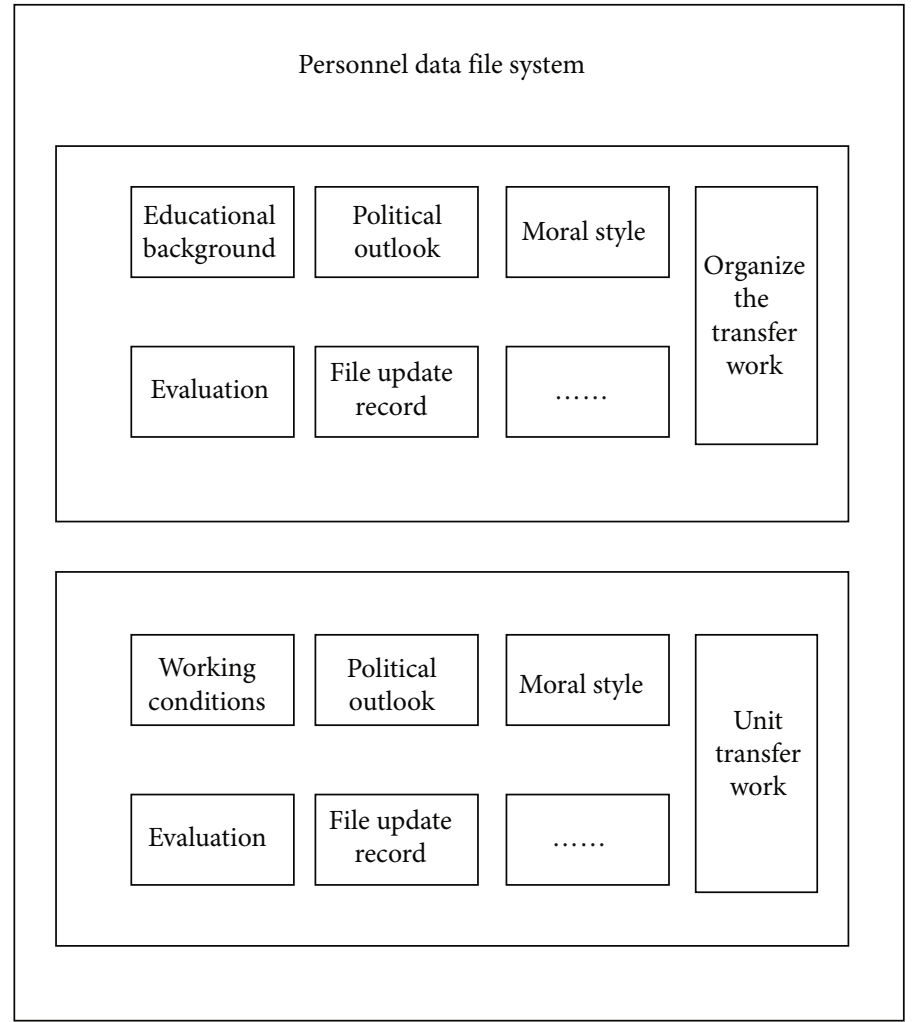

Figure 9: Personnel data file system.

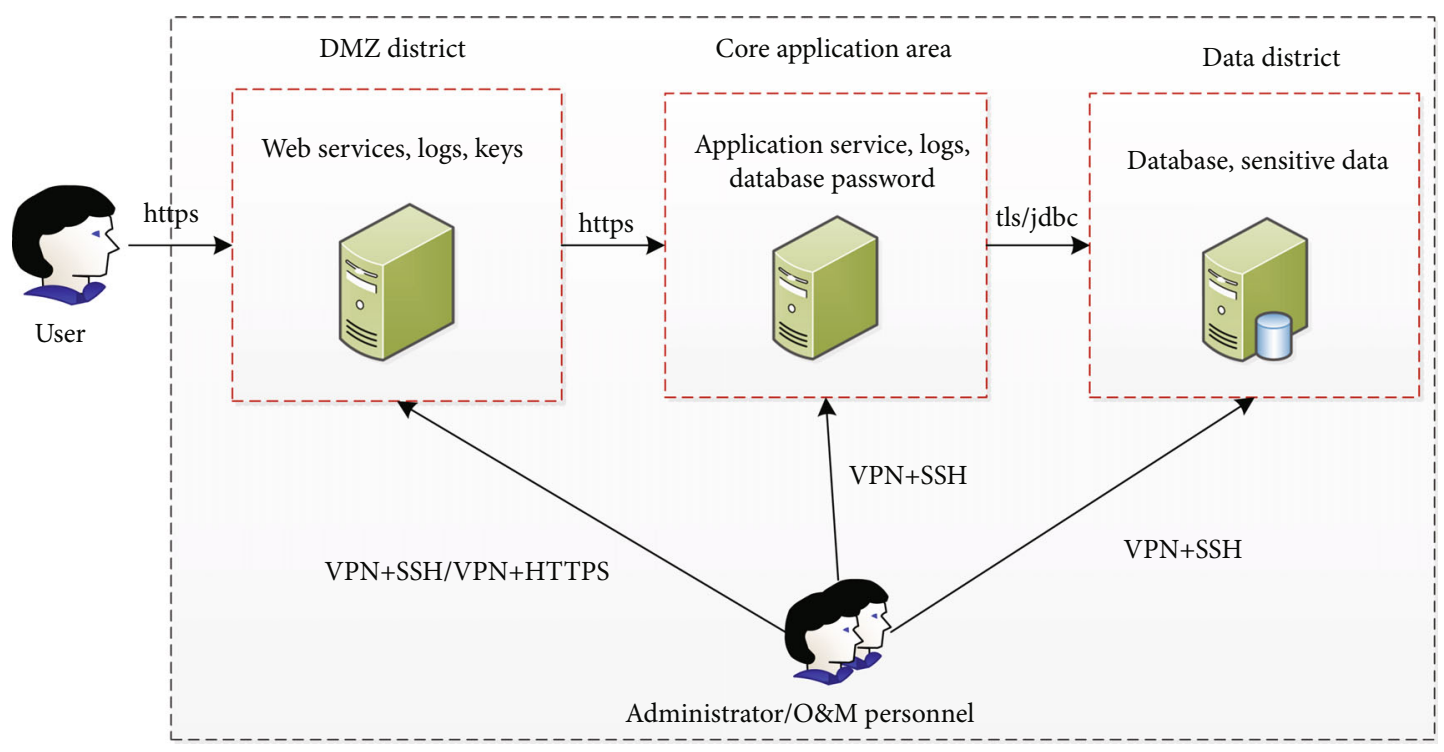

FIgURE 10: Security architecture diagram.

system itself, so we will specially design a security framework. Many criminals in the world make viruses (Trojan virus, Hack virus, Script virus, etc.) to steal information and data for illegal activities. The most terrible thing about viruses is that they infect computers through various channels and cause serious damage, which can lead to the destruction of data files and the paralysis of the network. We must focus on data security issues, maintain and update the system for a long time, make up for loopholes, and pre- vent the system from being attacked or crashing. The security architecture is shown in Figure 10.

3.2.2. Payment Security. The popularity of online shopping promotes the change of payment methods. Due to the development of information technology and communication industry in China, besides cash payment, credit card, or bank card payment, mobile phone scan code payment or two-dimensional code payment has become a mainstream 


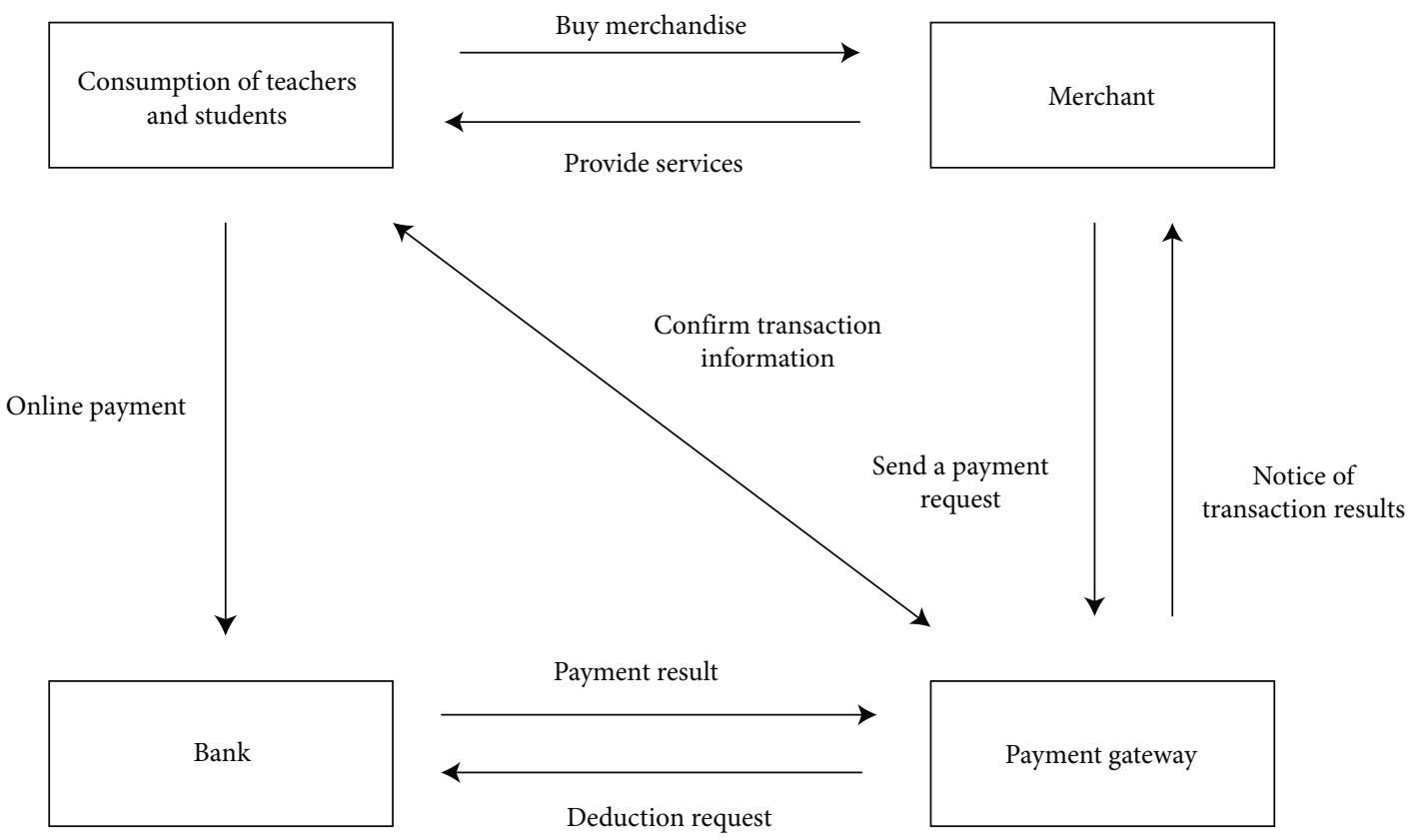

Figure 11: Electronic payment process.

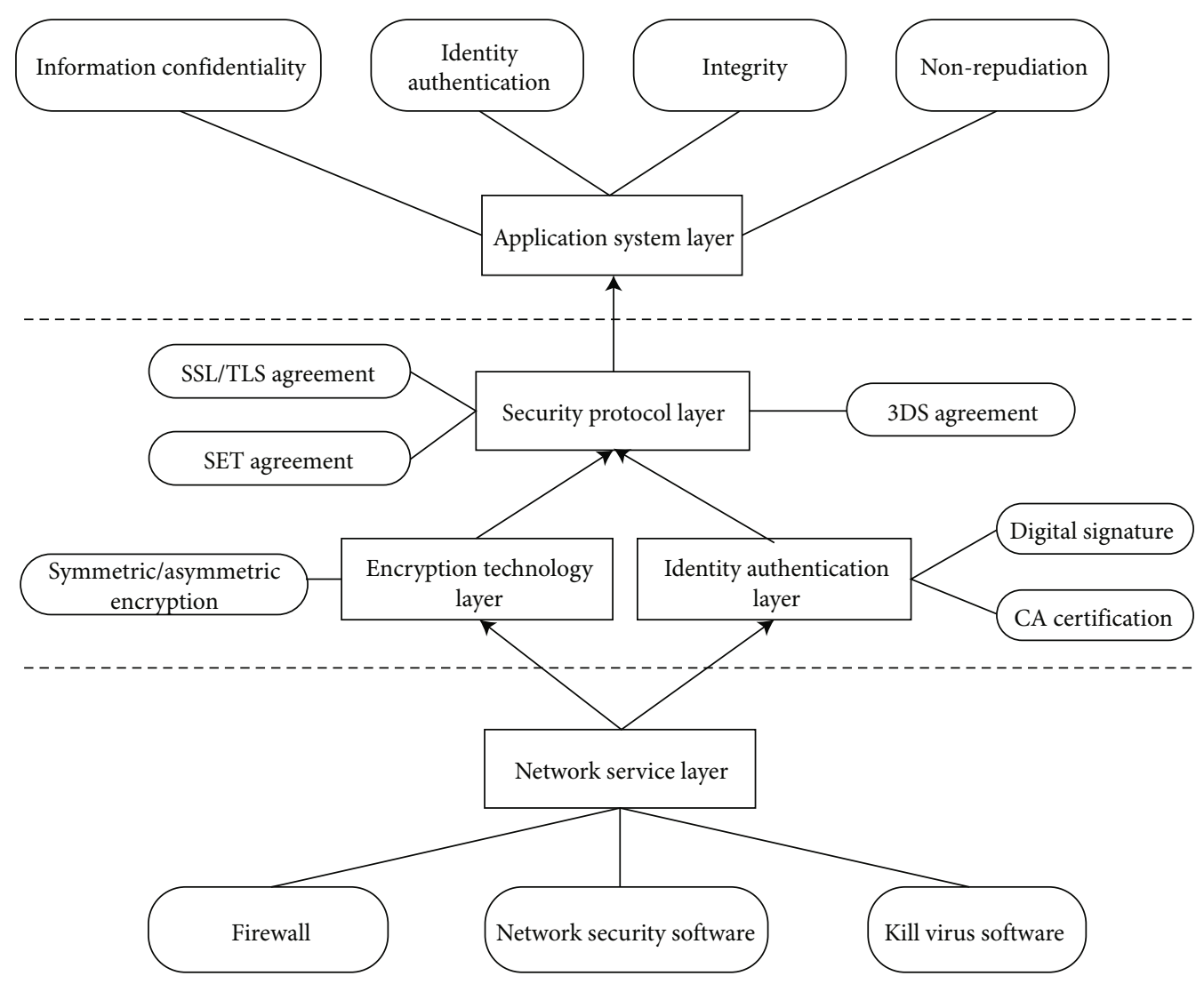

FIGURE 12: Electronic payment security technology.

trend. But the popularity of online payment also makes criminals eager to move. They have devised all kinds of network traps, which are difficult to capture telecom frauds and difficult to guard against malicious applications. Many people were cheated out of a lot of money because they did not pay attention for a while. Teachers and students on campus are also highly deceived places. As shown in Figure 11, it is an electronic payment flow chart.

As shown in Figure 12, it is a design drawing about electronic payment security technology. 


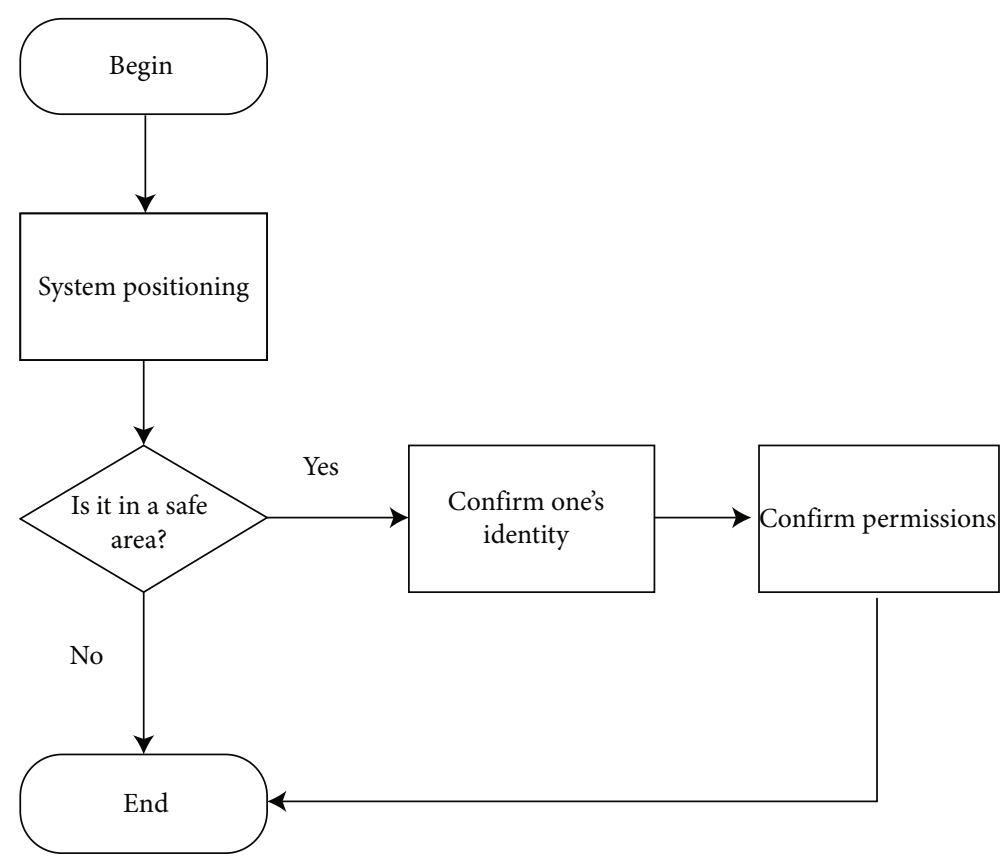

FIgure 13: Positioning system.

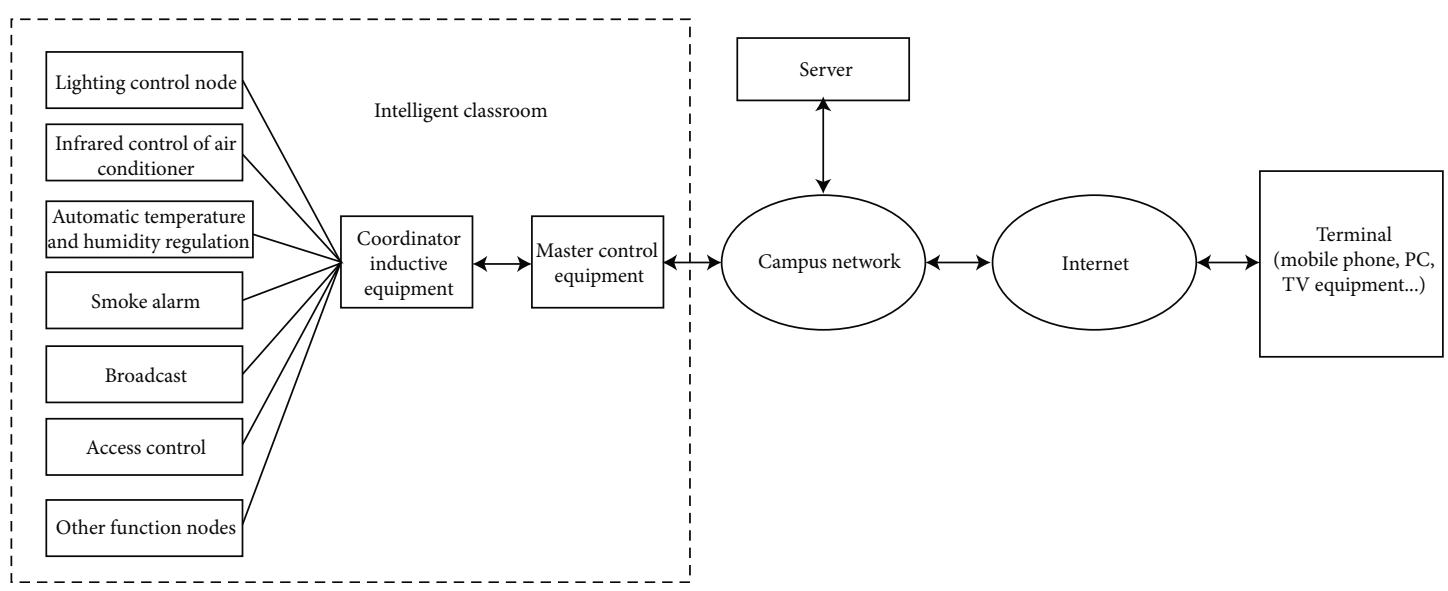

FIGURE 14: Functional structure diagram of intelligent classroom.

3.2.3. Positioning System Usage. In order to ensure the safety of school resources and the safety of teachers and students when they are mobilized, the system will use the school positioning system (generally placed on the virtual campus APP and various school infrastructures) to identify whether personnel are in the safe area, and only after confirming their identities and authorities can various resources be called to ensure personal safety. Figure 13 shows a flowchart of the positioning system.

\subsection{Convenience Services}

3.3.1. Intelligent Control of Classroom Equipment. Old-fashioned classroom conditions are average, There are deficiencies in many aspects, such as air circulation, difficult debugging of projection equipment, too old-fashioned computers, and serious water and electricity consumption. After the classroom is updated, a new intelligent integrated classroom will be built, which can easily meet the requirements of teachers and students, and will be more conducive to teachers and students to carry out various teaching activities and even provide distance teaching services for students. The schematic diagram is shown in Figure 14.

3.3.2. Intelligent Control of Laboratory Equipment. Laboratory is a very important part in scientific research, teaching, and research. Experimental equipment and utensils should be more accurate and strict, and there should be a safety protection system to ensure the safety and integrity of experimental equipment. Special personnel should regularly check and maintain the cleanliness of the laboratory and check the laboratory situation. The structure is shown in Figure 15. 


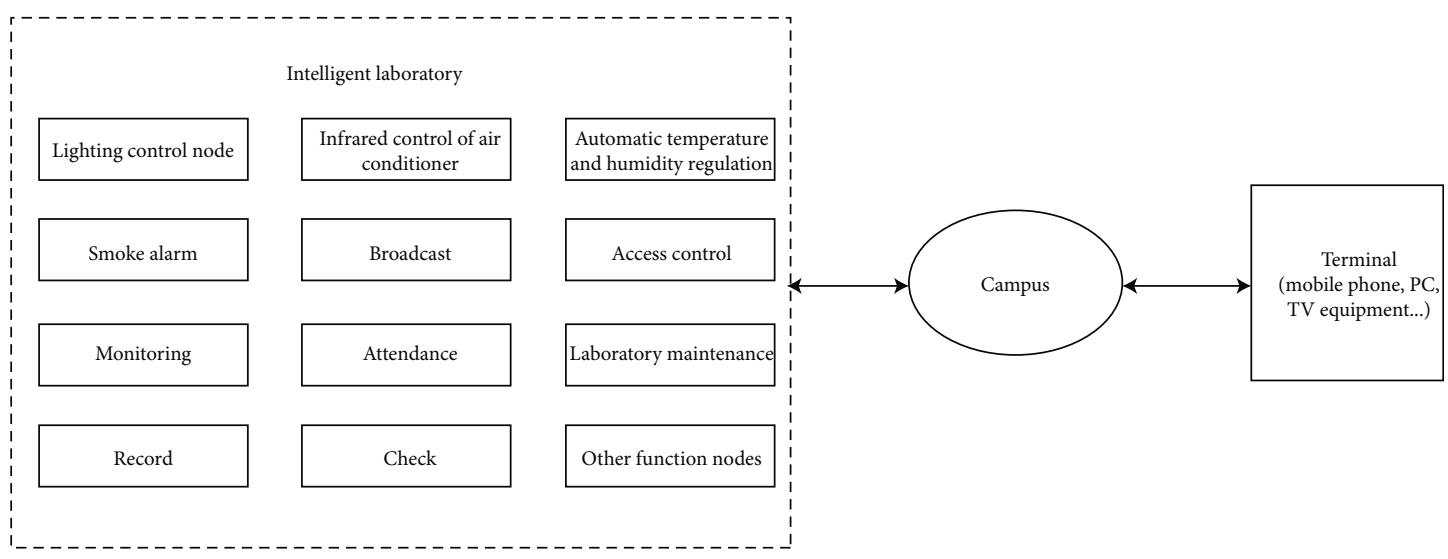

FIGURE 15: Functional structure diagram of intelligent laboratory.

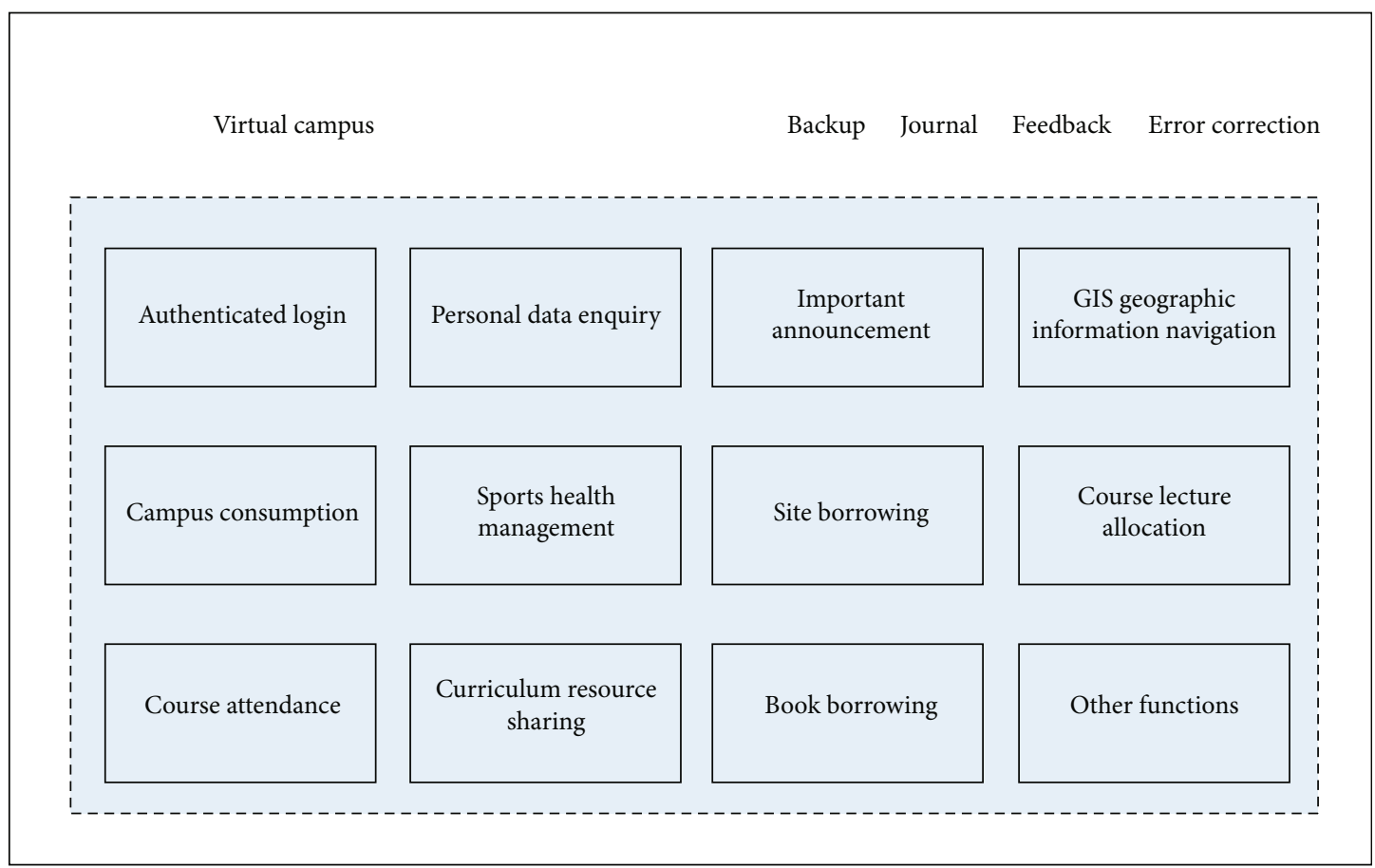

Figure 16: Virtual campus.

TABLE 1: Server requirements.

\begin{tabular}{lc}
\hline Hardware platform type & PC server \\
\hline CPU & $6 \mathrm{G}$ \\
Memory & $8 \mathrm{G}$ \\
Hard disk & $60 \mathrm{G}$ \\
Operating system & Windows or Linux \\
Database management system & Oracle \\
Description & According to the requirements \\
& of data exchange \\
\hline
\end{tabular}

3.3.3. Application of Face Recognition. The traditional identity authentication method, which is manually checked and approved or card-type, consumes manpower and material resources and is prone to flaws, which causes hidden dangers
TABle 2: Development environment.

\begin{tabular}{lc}
\hline Category & Describe \\
\hline Operating system & Win10 \\
IDE & 2021.1 .1 \\
JAVA & JDK15 \\
Database & Oracle $\backslash$ MySQL \\
Application server & Tomcat8.0 \\
\hline
\end{tabular}

to campus security. Therefore, using artificial intelligence technology and Internet of Things technology, we introduce system equipment with face recognition application and place it in school gates, dormitories, laboratories, study rooms, libraries, and other access control places that need identity verification. Teachers and students only need to 


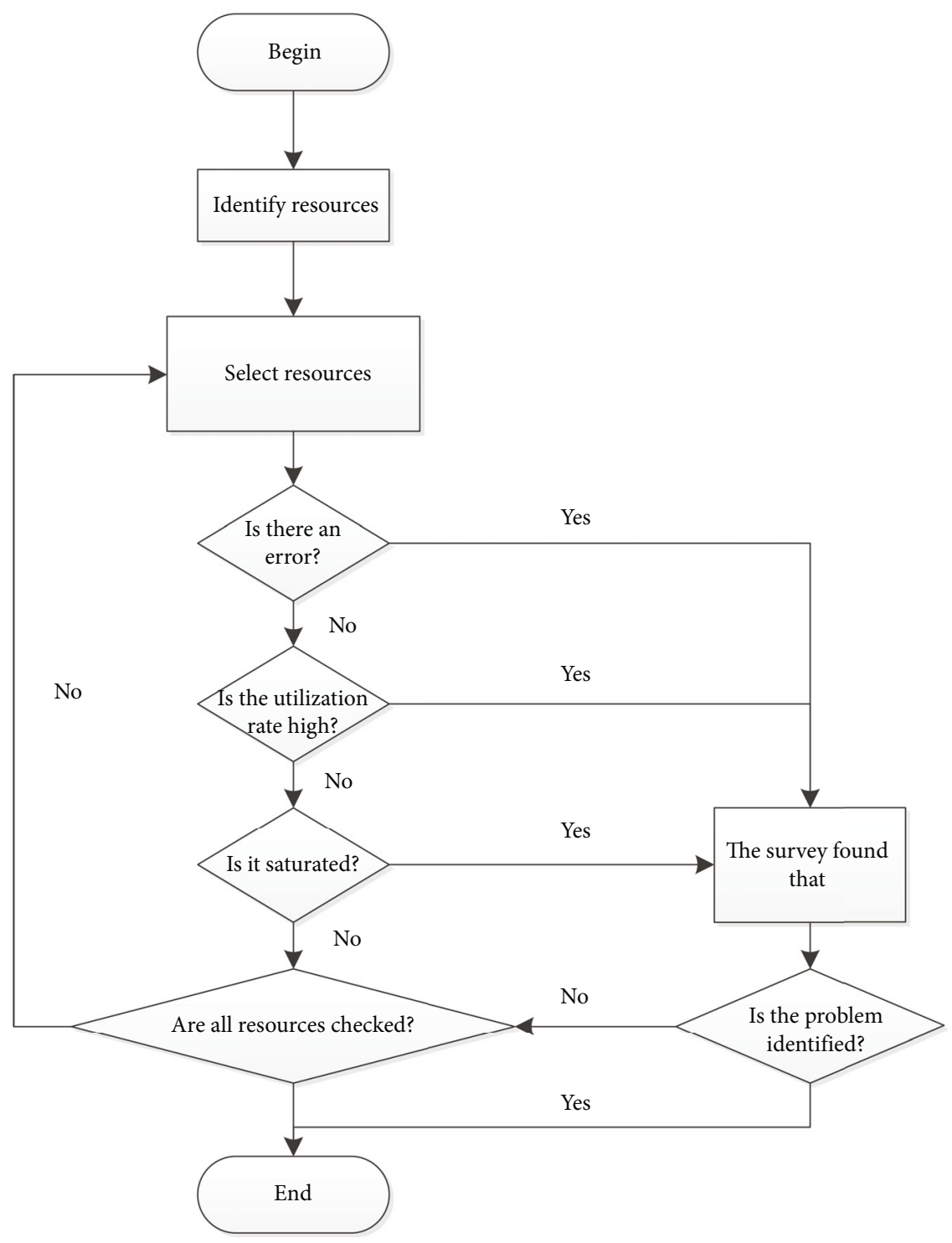

FIGURE 17: USE method.

TABLE 3: UI testing.

\begin{tabular}{lcc}
\hline Number & Test content & Test results \\
\hline 1 & Home navigation position & Normal \\
2 & Navigation bar content layout interface & Normal \\
3 & layout & Normal \\
4 & Interface layout & Normal \\
5 & Text display & Normal \\
6 & Font size & None \\
7 & Garbled code & Normal \\
8 & Hyperlink & Accord \\
9 & Color style & with \\
10 & Shortcut key & Normal \\
11 & Options button & Normal \\
12 & Text box, dialog box & Normal \\
\hline
\end{tabular}

complete the step of "brushing their faces," and they can use the corresponding venues and equipment resources according to their respective authorities. In this way, the inconvenience caused by numerous certificates is perfectly solved, and the work problems such as manpower, material resources, and time cost are greatly reduced. For outsiders, the system will give corresponding registration or alarm, which greatly improves the security of campus.

3.3.4. Virtual Campus Services. Virtual campus services include personal data inquiry, important announcement, GIS geographic information navigation, campus consumption, sports health management, venue borrowing, course lecture distribution, course attendance, course resource sharing, book borrowing, and other services. Teachers and students can enjoy convenient services only by logging in to APP or website on PC or mobile phone and authenticating their identities. The specific system interface of virtual campus service is shown in Figure 16. 
TABLE 4: Compatibility testing.

\begin{tabular}{lrl}
\hline $\begin{array}{l}\text { Number } \\
1\end{array}$ & It can be installed and enabled normally on different platforms, without card machine or flashback phenomenon. & Pass \\
2 & Login, page browsing, search, comment, and other interfaces have no deformation, occlusion, uncoordinated size, and \\
other problems and can be scaled and displayed at different resolutions. & Pass \\
3 & Verify that interactive controls such as text boxes and keys in the interface can click and respond normally. \\
4 & Verify that the controls in the interface can load network content, and the icons and texts of a single table item/list & Pass \\
5 & Verify that the font and resolution in the interface are scaled to a certain extent.
\end{tabular}

TABLE 5: Response time of original system.

\begin{tabular}{lcccccc}
\hline Concurrent request traffic & 100 & 1000 & 1900 & 2800 & 3700 & 4600 \\
\hline Average response time per request $(\mathrm{ms})$ of the original system & 25 & 100 & 168 & 228 & 307 & 411 \\
\hline
\end{tabular}

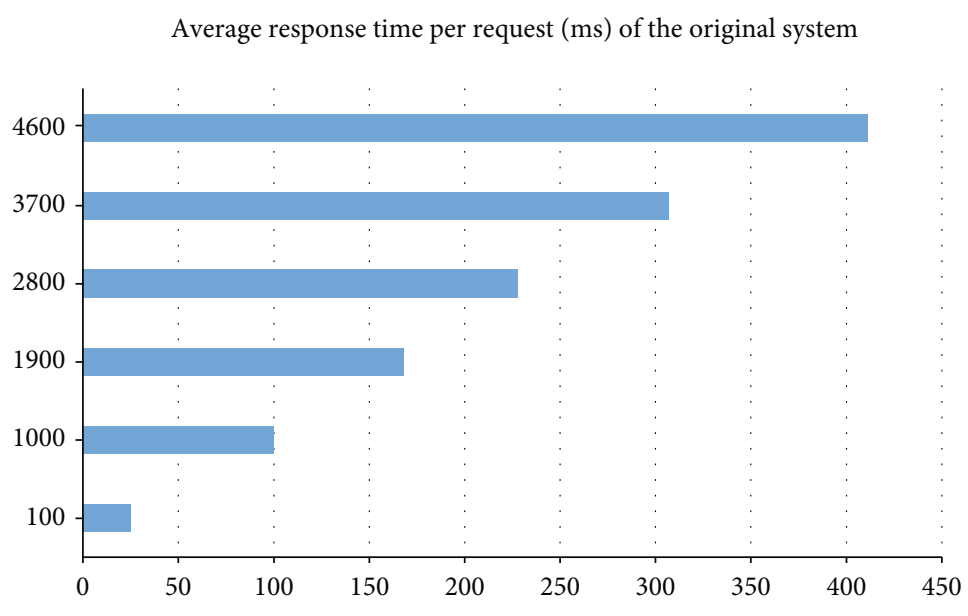

FIGURE 18: Response time.

\section{System Optimization Research}

The performance optimization of the system is not simply to detect one by one or to wait for feedback from users when they find problems. We should first automatically monitor performance problems and analyze them according to data. This is a long-term work, which requires continuous optimization research.

4.1. Caching. Caching technology can help us to develop high-performance and high-availability applications, save resources, and achieve optimization. We will cache data and computation results, as well as domain name resolution and resource objects themselves, which have been accessed, and they are likely to be used again in the future. This can reduce the waste or consumption of system resources and network resources to a certain extent.

4.2. Inertia. In order to save system resources, the system delays the calculation to some extent. When necessary, eliminate those parts that do not need to be calculated, and carry out the most precise calculation. This mode of operation can make the system have a "gap" to rest. Instead of running at high speed for a long time, it will cause irreversible damage to the life and performance of the system and cause a lot of troubles to maintenance personnel.

4.3. Code Quality. Excellent code is often efficient, usually with comments and code; code efficiency is very good, saving a lot of unnecessary work and trouble. When doing some optimization work, we should carefully modify our code unless we have to, because a little change can cause serious impact. The quality of the code and the logic of the code are important. Therefore, it is proposed that we should not optimize too early or overoptimize.

\section{System Function Test and Analysis}

Using professional testing system tools to test the campus education information system, according to the experimental results, the experimental analysis is given to determine the future improvement scheme and optimize the performance and function of the detailed system. 
TABLE 6: Response time of new system.

\begin{tabular}{|c|c|c|c|c|c|c|}
\hline Concurrent request traffic & 100 & 1000 & 1900 & 2800 & 3700 & 4600 \\
\hline Average response time per request for new system (ms) & 10 & 57 & 123 & 196 & 249 & 336 \\
\hline
\end{tabular}

Average response time per request for new system (ms)

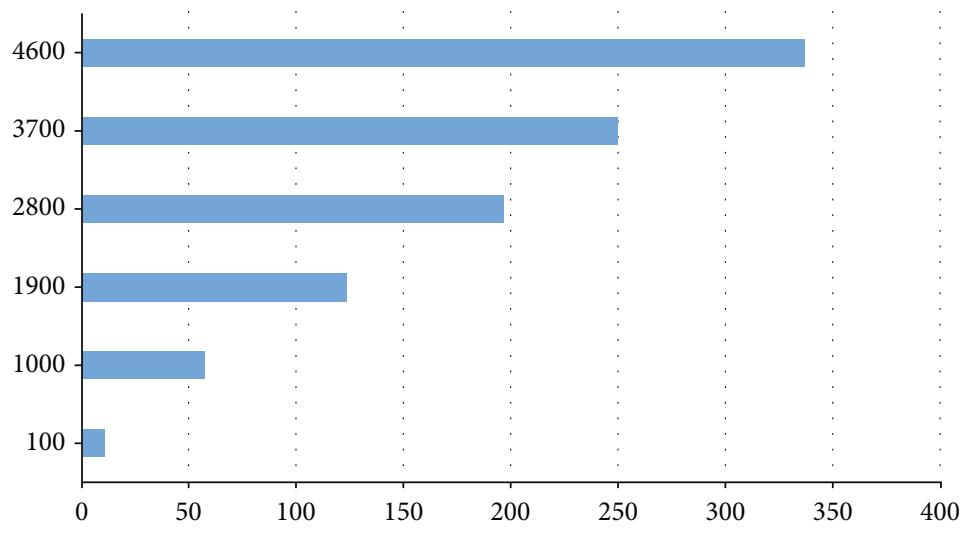

Figure 19: Response time.

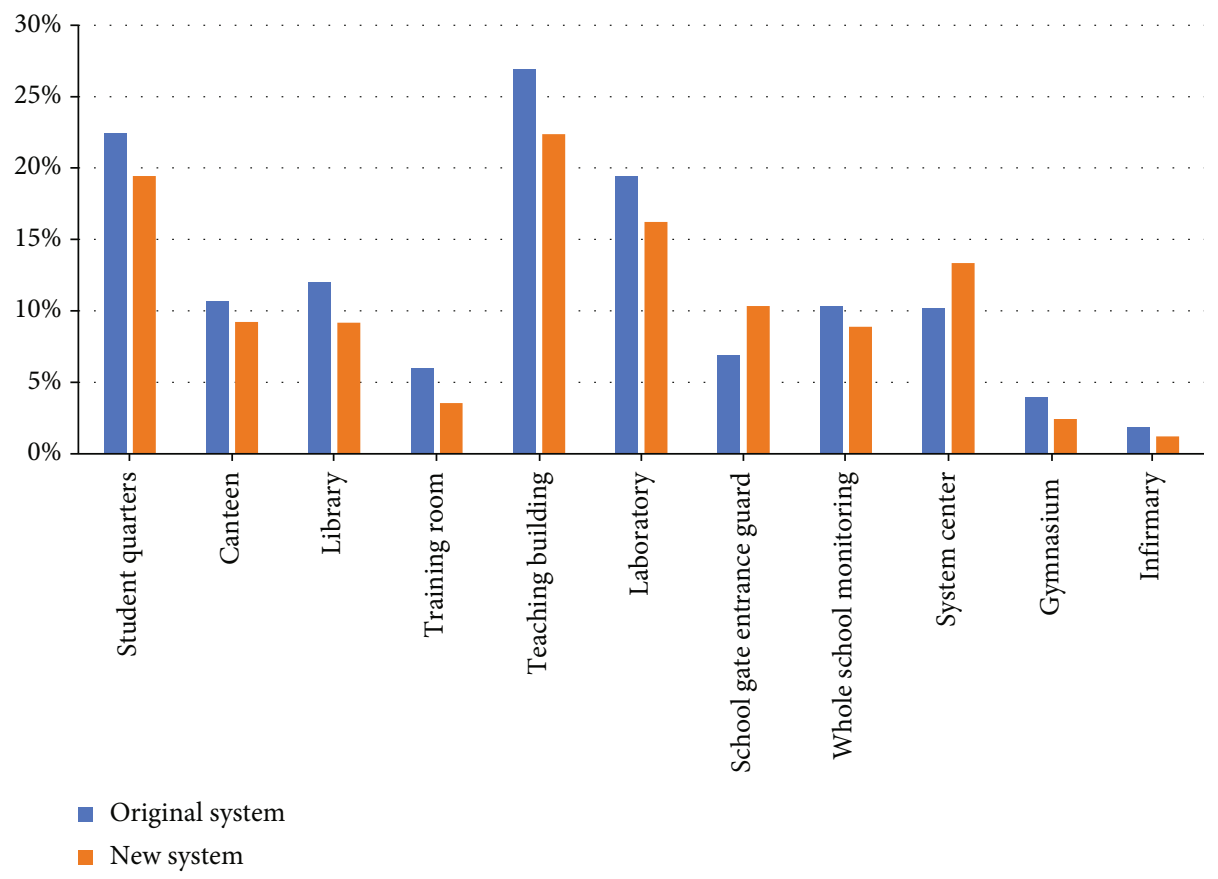

Figure 20: Comparison of regional power consumption between the original system and the new system.

5.1. Running Environment. The environment in which the system runs is shown in Tables 1 and 2.

5.2. USE Method for Performance Analysis. Check the utilization, saturation, and errors of all resources, as shown in Figure 17.

5.3. UI Testing. Through the Google Chrome browser manual operation identification detection, the main test platform operation is interface rationality. The test results are shown in Table 3.
5.4. Compatibility Testing. Test the compatibility of the system with software and hardware, as shown in Table 4.

5.5. System Performance Comparison. We will simulate two systems, one is the system before the transformation, and the other is the newly designed campus education information system. Because it is a simulation system, we consider many factors, such as cost, time, and experimental conditions. According to past experience, we reduce the system to an equal scale, which is convenient for the experiment. 
TABLe 7: Data of the original system and the new system.

\begin{tabular}{lcccccccccccc}
\hline Test point & T1 & T2 & T3 & T4 & T5 & T6 & T7 & T8 & T9 & T10 & T11 & T12 \\
\hline Original system & 4 & 5 & 5 & 3 & 6 & 3 & 2 & 5 & 1 & 5 & 6 & 4 \\
New system & 5 & 6 & 6 & 5 & 5 & 7 & 5 & 5 & 7 & 4 & 5 & 6 \\
\hline
\end{tabular}

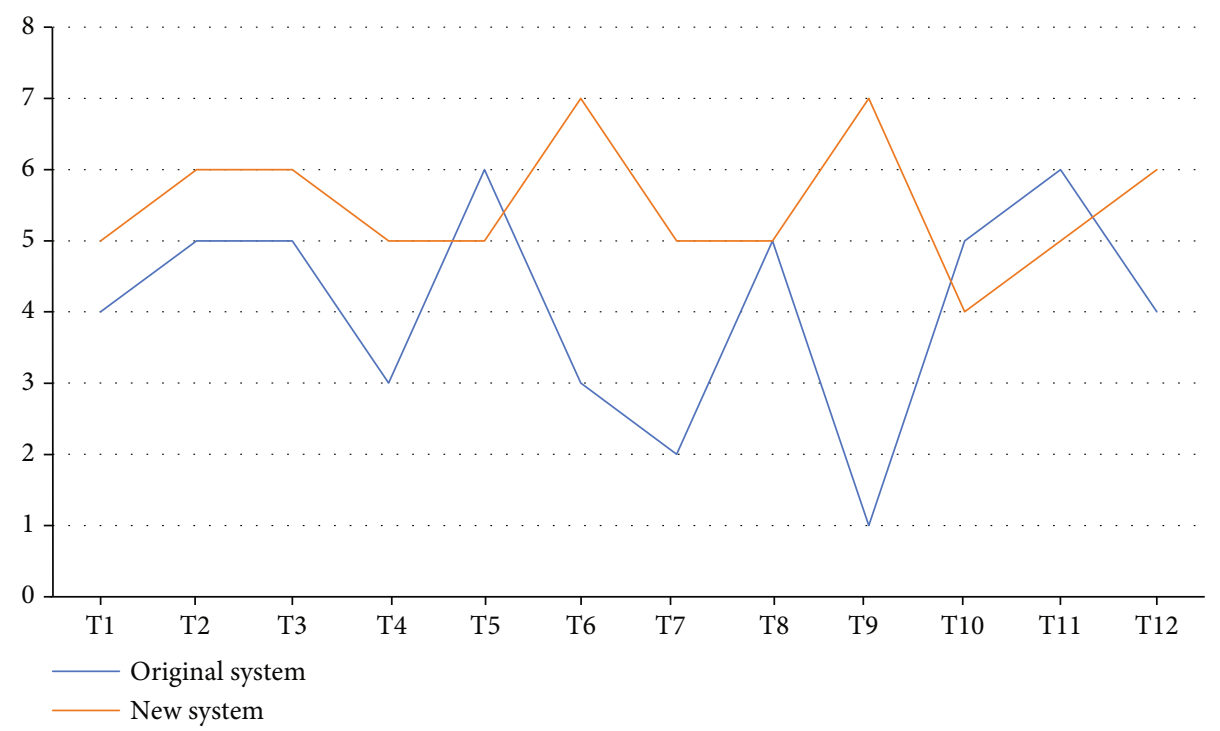

Figure 21: Data comparison diagram.

5.5.1. System Response Time. Response time refers to the time taken to execute a request or task. Response time means whether the performance of the system meets the requirements and whether it can bring smooth use effect. We set up six groups with visits of 100, 1000, 1900, 2800, 3700, and 4600 .

(1) The data of the original system are shown in Table 5.

The average response time per request of the original system is shown in Figure 18.

(2) Data for the new system are shown in Table 6.

The average response time per request for the new system is shown in Figure 19.

(3) The following is the analysis of experimental results:

Comparing the data of the original system with the new system, it is not difficult to find that after adopting the Internet of Things and artificial intelligence technology, the average response time of our system for each request is obviously reduced, which is $21.6 \%$ less than that of the original system, and the working efficiency of the system is greatly improved.

5.5.2. Area System Power Consumption. In response to the national call to save resources, the power consumed by the system is also an important index to test the system performance.
(1) The regional data of the original system and the new system are shown in Figure 20.

(2) The following is the analysis of experimental results:

We can clearly see from the figure that most areas of the new system consume less power than the original system, and the overall power consumption decreases by $1.43 \%$ on average. Only the school access control and system center have different increases in power consumption.

5.5.3. Usability Testing. There are 12 test points in this part of the test, which test whether the software, hardware, and network conditions meet the requirements and the users' evaluation feelings. The test part is the user's feeling after using the system for a long time (the time is set to 30 days): 1 stands for very bad, 2 stands for very bad, 3 stands for bad, 4 stands for average, 5 stands for good, 6 stands for excellent, and 7 stands for perfect.

(1) Data comparison between the original system and the new system is shown in Table 7.

The comparison diagram between the original system and the new system is shown in Figure 21.

(2) The following is the analysis of the test results:

As can be seen from the chart, users' evaluation of the original system is very bad, showing extreme and fluctuating values. However, the evaluation of the new system is stable, 
TABLE 8: Effect of minimum support $(s)$ on performance.

\begin{tabular}{lccccccccc}
\hline Minsup & 1000 & 5000 & 10000 & 15000 & 20000 & 25000 & 30000 & 35000 & 40000 \\
\hline Time consumed (s) & 26 & 28 & 27 & 24 & 15 & 11 & 6 & 3 & 1 \\
\hline
\end{tabular}

TABLE 9: Impact of data volume $(d)$ on performance.

\begin{tabular}{lcccccccccc}
\hline Num/10000 & 10 & 20 & 30 & 40 & 50 & 60 & 70 & 80 & 90 & 100 \\
\hline Time consumed (s) & 27 & 63 & 86 & 112 & 139 & 144 & 189 & 203 & 243 & 299 \\
\hline
\end{tabular}

the use effect is very good, and the fluctuation value is very small.

5.6. Apriori Algorithm Analysis. The experimental setting data $(D)$ is 100000 pieces, and the minimum confidence $(C)$ is fixed at 0.75 without changing.

(1) Fixed data volume $(D)$ changes minimum support $(s)$ :

The data are shown in Table 8.

The time consumption of minimum support is shown in Figure 4.

(2) Fixed minimum support ( $s$ ) changes the amount of data $(D)$ :

The data are shown in Table 9.

The amount of data consumes time, as shown in Figure 5.

(3) The following is the analysis of experimental results:

As shown in the figure, the more data is, the more time it takes. When the amount of data is constant, the time decreases gradually with the increase of the minimum support.

\section{Conclusion}

To sum up, the algorithms and technologies used in this research have obvious progress and superiority. After the network upgrade, compared with the old and backward systems used in previous schools, the current new system has stronger update iteration, stronger intelligent optimization, and stronger user experience. However, it should be noted that our testing of the system is only in the initial stage. If we want to put it into the market formally, there are still more details to be improved and optimized in the process of putting it into use. With the passage of time and the update of technology, there is still many work that needs to be adjusted to be studied by later generations.

\section{Data Availability}

The experimental data used to support the findings of this study are available from the corresponding author upon request.

\section{Conflicts of Interest}

The author declares that there are no conflicts of interest regarding this work.

\section{References}

[1] X. U. Qing, "Design of intelligent campus multimedia interactive system based on internet of things technology," in Proceedings of 2019 International Conference on Virtual Reality and Intelligent Systems (ICVRIS 2019) Volume I.Ed, pp. 237240, Conference Publishing Services, 2019.

[2] X. Lv and M. Li, "Application and research of the intelligent management system based on internet of things technology in the era of big data," Mobile Information Systems, vol. 2021, 6 pages, 2021.

[3] C. Yu and Y. Hang, "Application of artificial intelligence robots in precise management of medical equipment in the context of the internet of things," in Proceedings of 2019 4th International Industrial Informatics and Computer Engineering Conference(IIICEC 2019), pp. 228-234, Ed. Francis Academic Press,UK, 2019.

[4] S. Zhao, "The development of artificial intelligence education resources under the background of the internet of things," in Proceedings of the 32nd China Conference on Control and Decision-making, .Ed, pp. 375-380, 2020.

[5] J. Zhang, Y. Ye, C. Hu, and B. Li, "Architecture design and demand analysis on application layer of standard system for ubiquitous power internet of things," Global Energy Interconnection, vol. 4, no. 3, pp. 304-314, 2021.

[6] L.-S. Chen, "Design and implementation of intelligent mobile information system for campus safety management," in The Third (2008) Annual Meeting of Chinese Management-Proceedings of Marketing Sub-meeting.Ed, pp. 132-139, 2008.

[7] Z. Zhu, "Research on the construction of efficient and intelligent campus based on the internet of things," in Proceedings of 2020 International Conference on Artificial Intelligence and Communication Technology(AICT 2020).Ed, pp. 287-290, Clausius Scientific Press, 2020.

[8] L. Rothnie, "Campus wide information system development at three UK universities,” Vine, vol. 23, no. 4, pp. 18-30, 1993.

[9] Y. Chen and Y. Wei, "On the application of big data and cloud computing in the smart campus," in Proceedings of 2019 4th International Industrial Informatics and Computer Engineering Conference (IIICEC 2019).Ed, pp. 223-227, Francis Academic Press, UK, 2019.

[10] Q. Yin, "Design of campus management information system based on intelligent sensor network," Journal of Guangdong Polytechnic Normal University, vol. 33, no. 9, pp. 8-10, 2012. 
[11] N. ZHANG, "A campus big-data platform architecture for data mining and business intelligence in education institutes," in Proceedings of 2016 6th International Conference on Machinery, Materials, Environment, Biotechnology and Computer(MMEBC 2016).Ed, pp. 313-319, 2016.

[12] S. Li and M. Li, "Research and practice of constructing " $5 \mathrm{~A}$ model intelligent campus in all aspects" in higher vocational colleges under the background of education informatization 2.0," in Proceedings of 2019 3rd International Conference on Education,Management Science and Economics(ICEMSE 2019).Ed, pp. 484-487, Atlantis Press, 2019.

[13] T. Matsuo and T. Fujimoto, "A new lecture allocation support system based on users' multiple preferences in campus information systems," International Journal of Computational Intelligence \& Applications, vol. 6, no. 2, pp. 245-256, 2006.

[14] X. Cai, K. Zang, J. Li, and College of Information Engineering North China University of Technology Beijing, 100144, China, "Design and realization of online virtual campus system," in Proceedings of 2010 Third International Conference on Education Technology and Training.Ed. Xueli Zhou, pp. 159-161, Institute of Electrical and Electronics Engineers, Inc, 2010.

[15] P. Heping and Z. Jiao, "Design of virtual campus card system based on micro-service architecture," in Proceedings of the Seventh International Conference on Computing and Information Science.Ed, pp. 470-477, DEStech Publications, 2019.

[16] K. Yu, Z. Guo, and Y. Shen, "Secure artificial intelligence of things for implicit group recommendations," IEEE Internet of Things Journal, 2021.

[17] W. Wang, N. Kumar, J. Chen et al., "Realizing the potential of the internet of things for smart tourism with $5 \mathrm{G}$ and AI," IEEE Network, vol. 34, no. 6, pp. 295-301, 2020.

[18] K. Yu, M. Arifuzzaman, Z. Wen, D. Zhang, and T. Sato, “A key management scheme for secure communications of information centric advanced metering infrastructure in smart grid," IEEE Transactions on Instrumentation and Measurement, vol. 64, no. 8, pp. 2072-2085, 2015.

[19] W. Wang, F. Xia, H. Nie et al., "Vehicle trajectory clustering based on dynamic representation learning of internet of vehicles," IEEE Transactions on Intelligent Transportation Systems, vol. 22, no. 6, pp. 3567-3576, 2021. 